\title{
DIVERSIDADE EM CURSO DE ENGENHARIA NA PERSPECTIVA DE ESTUDANTES COM HABILIDADES \\ NO USO DE SOFTWARES
}

Cládice Nóbile Diniz,

Universidade Federal do Estado do Rio de Janeiro

\section{Rosemeire de Araujo Rangni}

Universidade Federal de São Carlos

\section{Resumo}

$\mathrm{O}$ artigo busca investigar a identidade cultural de alunos de um curso de engenharia sob a ótica dos que podem ser apontados com potencial elevado no uso de softwares e internet. Explica que a identidade cultural de um grupo tratase da imagem mental de como ele é percebido pelos outros, sendo possível delineá-la por características comuns de seus indivíduos, levantadas a partir de questionários autoavaliativos. Esse desenho, ao destacar o que é comum, estabelece também a ideia da diferença. $\mathrm{O}$ referencial teórico pautou-se em autores de estudos culturais e de educação especial e na legislação. A metodologia foi exploratória e de campo. Os resultados sugerem que o sucesso escolar dos ingressantes aparenta vir do esforço individual, familiar e das escolas onde estudaram. Concluiu-se sobre o papel da universidade quanto a prover fluência tecnológica e pela pertinência dos conhecimentos da educação especial e estudos culturais em contribuição interdisciplinar.

Palavras-chave: Altas Habilidades ou Superdotação em softwares; Diversidade; Curso de Engenharia de Produção. 


\title{
DIVERSITY IN THE ENGINEERING COURSE IN THE PERSPECTIVE OF SKILLED STUDENTS IN SOFTWARES
}

\begin{abstract}
The paper reaches to investigate the cultural identity and diversity on students in the engineering course under the view who can be pointed out with high potential in the use of software and internet .It explains that cultural identity of a group is the mental frame of them and how they are perceived for the others. It's possible to design the common characteristics among the individuals by the evaluation surveys. This frame points out what is common establishes the idea of difference. The theoretical framework was based in cultural studies and special education authors and legislation. The methodology used for the study was exploratory and field. The results suggest that the academic success of fresh students can come in the individual effort, family, and schools where they studied. It's concluded about the role of the university in providing technological fluency and relevance of the special education knowledge for cultural studies in interdisciplinary contribution.
\end{abstract}

Keywords: High skills or giftedness in softwares; Diversity; Production Engineering Course. 


\section{Introdução}

Os estudantes que optam por estudar engenharia são vistos, em geral, como indivíduos com conhecimentos e habilidades muito bons em conteúdos de ciências exatas, destacando-se em matemática. Essas observações se confirmam no senso comum devido à nota mínima exigida nos exames para ingresso em cursos de engenharia, que costuma ser maior do que em muitos outros cursos, situação em que as notas em conteúdos de base matemática exercem um importante papel.

No entanto, não é claro se essas competências foram adquiridas até essa fase da vida por uma formação que se voltou para esse propósito e muita dedicação, ou se é uma dotação específica. Para embaralhar qualquer conclusão empírica, observa-se que esses estudantes ao cursarem disciplinas de ciências exatas, nos primeiros anos da vida universitária, nem sempre se mantém com a mesma performance, podendo apresentar insucesso repentino em disciplinas ditas "duras"; um fator que pesa na taxa de evasão, se não causal, ao menos interveniente.

Considerando-se a evasão, um primeiro olhar sugere ser ocasionada por razões de disponibilidade de tempo para o estudo devido ao trabalho, compatibilidade do horário do curso com a do trabalho, desencanto com a carreira relacionada ao curso e descompasso didático-pedagógico do ensino proposto com a realidade do aluno.

Tendo essas questões em pauta e não se dispondo de informações sobre os ingressantes do Curso de Engenharia de Produção em quantidade suficiente para subsidiar a ação docente desejada, propôsse uma pesquisa socioeconômica e cultural para levantar a identidade cultural do grupo e sua diversidade, especialmente, quanto àqueles seus componentes que podem ser apontados com indicadores de altas habilidades ou superdotação ${ }^{1}$, especificamente, no uso de softwares de

\footnotetext{
${ }^{1}$ Denominação oficial da Lei de Diretrizes e Bases da Educação Nacional (BRASIL, 1996), alterada pela Lei12.796 (BRASIL, 2013).

Olh@ res, Guarulhos, v. 2, n. 1, p. 422-440. Maio, 2014.
} 
computação pessoal e internet. Para tanto, com esses indicadores, busca-se facilitar o atendimento educacional especializado e alinhar o curso em questão ao Decreto No 7.611, de 17 de novembro de 2011 (BRASIL, 2011).

A motivação em fazer na pesquisa corte específico em altas habilidades ou superdotação foi pela hipótese de ingressantes com essa condição, devido às considerações inicialmente apresentadas.

Devido ao amplo leque de disciplinas da área de exatas e tecnologia, escolheu-se pesquisar as habilidades no uso de software, por serem não somente da área de conhecimento abordada, mas, também, sua aquisição implicar em atitudes de autonomia, curiosidade e persistência, que são características muitas vezes de pessoas com altas habilidades ou superdotação de acordo com Alencar e Fleith (2001), Sabatella (2005), Guenther (2011), Freitas e Pérez (2012), entre outros.

Quanto ao recurso adotado, o da identidade cultural, é utilizado nos estudos culturais para se conhecer um determinado grupo a partir do levantamento de signos que constituem a imagem mental com que se identifica o coletivo focalizado (BHABBA, 1998; SAHLINS, 2007; WOODWARD, 2009).

Os estudos de multiculturalidade e diversidade são importantes porque tornam possível se destacar subgrupos com questões a serem social e culturalmente resolvidas, como as de ser provido ou não de suficientes habilidades tecnocomputacionais para o êxito profissional. Também, aqueles decorrentes de características culturalmente depreciadas e cujo subgrupo é tratado de forma que se mascaram ou atenuam as situações de desfavorecimento, como são os de gênero e com deficiências e/ou altas habilidades ou superdotação. 


\section{Objetivos}

\section{Geral}

Apresentar os resultados de uma investigação de identidade cultural e diversidade aplicada a ingressantes de um curso de Engenharia de Produção, apontando possíveis alunos com altas habilidades ou superdotação no uso de softwares e internet.

\section{Específicos}

Analisar dados socioeconômicos e culturais dos alunos, coletados de forma quantitativa, por meio do software livre de análise estatística e probabilística (PSPP), distribuído por Boaventura (2011).

\section{Metodologia}

A metodologia adotada na pesquisa se deu por meio de pesquisas exploratórias para levantamento da identidade cultural dos estudantes do primeiro período do Curso de Engenharia de Produção e de sua diversidade. Contou-se com pesquisa de campo apoiada em questionário semiestruturado que operacionalizou 136 variáveis em dez tópicos para coletar dados socioeconômicos e culturais dos participantes.

Os dados coletados no questionário foram tratados quantitativamente, por meio do software livre de análise estatística e probabilística (PSPP), distribuído por Boaventura (2011).

Também como pesquisa documental empregada, foram investigados os históricos escolares dos participantes.

Os alunos investigados são os ingressantes das quatro primeiras turmas semestrais, de 2010 e 2011, que somam um total de 78 indivíduos do Curso de Engenharia de Produção da Universidade Federal do Estado do Rio de Janeiro. É um curso gratuito, em período vespertino-noturno e que prevê o ingresso pelo Exame Nacional do Ensino Médio (ENEM) para formar turmas semestrais de até 25 alunos. Não houve ingresso por cotas no período investigado.

Olh@ res, Guarulhos, v. 2, n. 1, p. 422-440. Maio, 2014. 


\section{Identidade de grupo e multiculturalidade}

A identidade cultural de um indivíduo ou grupo, também denominada simplesmente identidade, é um objeto somente teórico e conceitual, afirma Bhabba (1998). O mencionado autor explica que se refere à imagem gerada na mente dos que tecem ponderações a seu respeito. Essa imagem forma-se marcando mentalmente para o sujeito quais são suas diferenças em relação aos outros, gerando um conjunto que lhe é representativo.

Segundo explicação creditada por Woodward (2009), à antropóloga Mary Douglas, essa ordenação seletiva da realidade pelas estruturas cognitivas é mediada pela cultura. Ao se destacar e posicionar as diferenças percebidas nas coisas e pessoas produzem-se seus significados, com isso, ocasiona a reprodução das relações sociais. Esse mecanismo, segundo Sahlins (2007), torna cultural o ato de perceber algo e atribuir significados, levando os sentidos a distinguir algumas diferenças reais e não a outras; ao implementar-se ou não no cérebro o que a cultura oferece.

Essa proposição, para Woodward (2009), que cita Hall (1997), é fundamentada na ideia de Émile Durkheim de que cada grupo tem sua vida social organizada e ordenada pelos sistemas de classificação de sua cultura, os quais agem a partir das falas e rituais, com cada coisa ou pessoa ganhando seu sentido no grupo pela linguagem, que as posiciona em relação às demais.

Contudo, Bauman (1999) assinala que nestes tempos pós-modernos ocorrem subgrupos, de tal maneira que a variabilidade cultural gerada cria resistências a uma rigidez classificatória, o que faz o poder da classificação passar a ter limites pela impossibilidade de se classificar, fragmentar e nomear as coisas sem ambivalências e/ou ambiguidades. Como consequência, os sistemas de poder gerados na cultura hegemônica ficam enfraquecidos. 
Uma consideração semelhante também se encontra em Canclini (2009), que pontua que as identidades se veem em remodelações constantes no que tange aos seus modos de ser e as suas relações sociais. Por elas serem apresentadas a outros modos de vida e condicionantes acabam levando-as a negociarem e confrontarem o poder por diferentes sistemas socioculturais gerando a multiculturalidade, devido à necessidade dos indivíduos de diferentes culturas conviverem bem.

A multiculturalidade é um tema-padrão que está presente em todos os ambientes, até mesmo naqueles que estimulam fortemente uma identidade hegemônica e, segundo Canclini (2009), Jullien (2009), Woodward (2009), Eagleton (2010), as questões a ela relacionadas sobressaem nos estudos culturais.

Bhabba (1998), Wallerstein (2006), Sahlins (2007) e Eagleton (2010) assinalam que os estudos culturais compõem uma área do conhecimento e que pesquisam os indivíduos que integram o grupo, inclusive as suas percepções sobre assuntos críticos, pressionam a sociedade atual, impactam culturalmente o coletivo exigindo posicionamento, de forma tal que se destacam como temas-padrões nas agendas políticas e na mídia, razão pela qual recebem a denominação de agendas.

A metodologia dessa área, para traçar a identidade cultural e a multiculturalidade, parte dos posicionamentos individuais manifestados sobre questões de agenda. Isso busca levantar pontos identificadores que reflitam posições coletivas para posicionar o grupo e destacar a sua concepção de vida social entre as diferentes e conflitantes concepções de vidas sociais que se observa existir, fato que propicia a Moreira e Silva (1995, p. 27) o comentário de que a cultura "é aquilo pelo qual se luta, e não aquilo que recebemos".

Entre as agendas atuais, destacam-se:

a) A informatização do mundo, pressionando por muitas habilidades em tecnologia da informação (SASSEN, 2007), a ponto de requerer o reconhecimento como tecnologicamente alfabetizado, segundo Diniz (2007), como também, ser conhecedor de softwares de processamento Olh@res, Guarulhos, v. 2, n. 1, p. 422-440. Maio, 2014. 
de texto, apresentação e navegação na internet e ser hábil em planilhas e banco de dados;

b) A ascensão da classe média e a da urbanização, destacado por Wallerstein (2006), que traz questões de renda e hábitos de entretenimento e lazer, entre outros; e

c) A diversidade cultural, que, conforme explica Lopes (2007), surge devido a características corporais, como gênero ou ter uma deficiência ou destacar-se com potencialidades acima da média em algum campo, nomeados com altas habilidades ou superdotação.

\section{Redução da multiculturalidade à diversidade}

Os grupos que compõem a multiculturalidade do tecido social têm as diferenças entre seus componentes articuladas por meio de identidades culturais específicas, o que leva a se fragmentarem em subgrupos.

As diferenças são ocasionadas por fatores e podem ser classificadas de acordo com sua origem, como individuais, do grupo e do contexto, de acordo com Gutierrez; Maz (2004). As mencionadas autoras citam o modelo de pesquisa proposto por Alvarez; Bisquerra (1996), no qual as diferenças étnicas, de gênero e socioculturais no grupo são explicadas por elementos do contexto escolar, familiar e social e por diferenças individuais. Sugerem que estas, por sua vez, são ocasionadas por etapas individuais de desenvolvimento, conhecimentos prévios, motivações, interesses, expectativas, estilos de aprendizagem e processos cognitivos específicos, sendo influenciadas pelo inter-relacionamento no grupo.

Com relação à construção de grupos fixos e preferenciais em salas de aula, Melo (2002, p. 72) analisando fenômenos de subjetividade, tece considerações sobre a formação de "panelinha", ou "panela", definindo-as como sendo um "grupo de pessoas que se escolhem mútua e consistentemente numa sala de aula". A mesma autora também destaca que apesar de ser considerado um fato normal e corriqueiro, a formação desses subgrupos é uma situação problemática

Olh@res, Guarulhos, v. 2, n. 1, p. 422-440. Maio, 2014. 
devido ao afastamento ou desconhecimento que é gerado entre os participantes de um subgrupo. Com respeito aos demais integrantes da classe, eles encontram um contraponto na necessidade de atender o sentimento de pertinência a um subgrupo, evitando-se o risco de sobrar, isto é, de não ser escolhido, de ser desprezado e (ou) desprezar.

Se a formação dos subgrupos eletivos é problemática e merece atenção a de subgrupos compulsórios não têm como deixar de ser, como é o caso daqueles formados por diferenças com marcas corporais. As diferenças quando podem ser detectadas por marcas corporais, que distingam os subgrupos que elas determinam, originam a diversidade cultural do grupo, o que é uma redução do conceito de multiculturalidade. Nos casos de subgrupos por diversidade cultural por marcas corporais -, a circunstância não só de sua formação, mas de toda a sua existência, pode ser crítica e levar os seus sujeitos a franco desfavorecimento (LOPES, 2007).

Omote (2010) alerta que nos casos de diversidade por deficiência e/ou altas habilidades ou superdotação o aspecto funcional da diferença é considerado como categoria social, com atributos, comportamentos e afiliação grupal os quais visam à adaptabilidade.

\section{Reconhecimento de casos e inclusão}

No Brasil, como nos outros países signatários da Declaração de Salamanca sobre Princípios, Políticas e Práticas na Área das Necessidades Educativas Especiais, da Organização das Nações Unidas, em 1994, todos os indivíduos devem estar integrados em sistemas educacionais nacionais regulares, inclusive aqueles que por condições físicas e/ou psíquica requerem atendimento especial, conjunto esse que abrange as pessoas que apresentam potencialidades elevadas - os denominados com altas habilidades ou superdotação.

A definição do que seja o aluno nessas condições encontra-se no documento Política Nacional de Educação Especial na Perspectiva da 
Educação Inclusiva, da Secretaria de Educação Especial (SEESP) do Ministério da Educação (MEC) (BRASIL, 2008) que informa:

\begin{abstract}
Alunos com altas habilidades/superdotação demonstram potencial elevado em qualquer uma das seguintes áreas, isoladas ou combinadas: intelectual, acadêmica, liderança, psicomotricidade e artes, além de apresentar grande criatividade, envolvimento na aprendizagem e realização de tarefas em áreas de seu interesse (BRASIL, 2008, p.9). Grifo nosso.
\end{abstract}

Essa definição implica em haver comprovação objetiva e lógica de sua ocorrência para que se possa dar como "demonstrado", o que torna circunscrito à esfera do que é comprovado por demonstração. A necessidade da comprovação é um aspecto comum entre indicadores de potencialidade elevada e de deficiência, situações que podem ocorrer em qualquer indivíduo.

Tentando explicar a ocorrência das altas habilidades ou superdotação, Guenther (2000) explicita sobre as faces dos talentos humanos quando os caracteriza como permanentes, isto é, ocorrências de talentos que surgem a cada geração, de forma inesgotável. Pontua também, a característica da diversidade, explicando que não há como prever que talentos venham a surgir ou florescer.

Sob a ótica da imprevisibilidade do surgimento dos talentos humanos a mesma autora (2006) pontua sobre o acaso:

\begin{abstract}
A força do acaso buscou identificar origens de sucesso. Como afirma Atkinson, os dois grandes determinantes de quase tudo na vida são frutos de acaso: a carga genética com se se nasce e o meio em que se é criado. Por ser ao acaso, em princípio não há aqui espaço para se exercer qualquer influência, pois, ao que se sabe, ao nível das pessoas, nada se pode fazer para controlar a força e direção do acaso (GUENTHER, 2006, p. 25).
\end{abstract}

Mesmo com a perspectiva do acaso, há porcentagens consideradas entre os estudiosos para o fenômeno das altas habilidades ou superdotação na população em geral como: 10\% para Gagné e 15 a $20 \%$ para Renzulli (RANGNI, 2012).

Olh@res, Guarulhos, v. 2, n. 1, p. 422-440. Maio, 2014. 
É importante assinalar, que o número de pessoas com deficiên cia estão mais ou menos pareado às porcentagens assinaladas anteriormente, às altas habilidades ou superdotação, levando a inferir que o fenômeno, tanto das altas habilidades ou superdotação como da deficiência nos indivíduos, podem vistas em comum, se forem olhadas pelo prisma da diferença.

No âmbito educacional, tanto as deficiências quanto as altas habilidades ou superdotação são contempladas como público atendido pela educação especial; em todos os níveis de ensino (BRASIL, 2011). Portanto, os estudantes do ensino superior que sejam identificados nesses grupos devem receber atendimento especializado.

Deve-se colocar para reflexão e discussão, que os alunos com altas habilidades ou superdotação nem sempre apresentam facilidade e agilidade em aprender, se analisarmos pelo viés intelectual. O que dizer daqueles alunos com fracasso escolar e que se destacam em outras áreas de domínio de capacidade? Lembramos que as áreas contempladas são seis quais sejam: inteligência geral, acadêmica, criatividade, artística, liderança e psicomotricidade (BRASIL, 2008). Não se pode esquecer, que os indivíduos podem apresentar uma área com limitação, mas se destacarem em outra ou outras, pela própria definição orientada no mesmo documento anteriormente "potencial elevado em qualquer uma das seguintes áreas, isoladas ou combinadas" (BRASIL, 2008, p.9) (grifo nosso).

Sobre o atendimento das altas habilidades ou superdotação no ensino superior, há necessidade de identificação, a fim de melhor atendê-los, conforme orienta Virgolim (2007, p. 15): “Os educadores que querem ajudar os jovens a obterem êxito no mundo atual devem estimular certos aspectos de sua personalidade que os permitam expandir seus talentos e aplicá-los em algum campo do conhecimento e da cultura". O Atendimento Educacional Especializado (AEE) é um serviço de educação especial organizado para apoiar os alunos com deficiência, com transtornos globais do desenvolvimento e com altas habilidades ou superdotação, os quais são definidos pela Política Nacional de Educação Especial na Perspectiva da Educação Inclusiva, da Olh@ res, Guarulhos, v. 2, n. 1, p. 422-440. Maio, 2014. 
Secretaria de Educação Especial (BRASIL, 2008) como público alvo da educação especial.

Na literatura pertinente à Educação Especial, há muitos estudos de pesquisa-ação, pesquisas participantes e pesquisas aplicadas a casos, não raro envolvendo a metodologia de pesquisa fenomenológica, talvez devido a haver mais casos de intervenções individualizadas sendo oferecidos para estudo, o que leva a impulsionar o surgimento de métodos e recursos que os apoiem. Villarraga, Martínez e Benavides (2004) citando Mönks e Mason (2000) informam haver classificado mais de 100 construtos, cada um baseado em definição específica para as altas habilidades ou superdotação, destacando-se os resultados e realizações.

Guenther (2000), Virgolim (2007), Chagas (2009), Delou (2010) apresentam instrumentos para operacionalizar a identificação. Esta, para Bates e Munday (2007), pode ser feita por observação direta dos professores e por conversas sobre o assunto, entre si e com os estudantes, valendo-se de mecanismos para dar objetividade à constatação individual.

Delou (2010) e Freitas e Pérez (2012) propõem a identificação em duas fases, uma prévia, de triagem dos que se destacam em autonomeação e nomeação por colegas, e outra, da identificação propriamente dita, por profissional especializado. Freitas e Pérez (2012) alertam que é possível haver mascaramento nas respostas de questionários de triagem, por razões de autoestima ou autoconfiança. Uma consideração importante quanto a características de pessoas com altas habilidades ou superdotação é assinalada por Freitas e Pérez (2012), sobre a leitura precoce e o elevado volume de leitura, com a média de 25 livros lidos fora dos exigidos pela escola, sendo 7 por ano. As referidas autoras informam, ainda, que em estudo sobre moralidade as ações de participantes com potencial superior foram regidas por valores éticos e morais. 


\section{Resultados}

Com o uso do software PSPP levantou-se sinais de precocidade na aprendizagem, de desempenho superior em habilidades tecnocomputacionais, de autonomia, pró-atividade, ética e de aprendizagem diferenciada, tendo em conta as suas vivências e opiniões.

A pesquisa documental mostrou que, o curso não teve caso de alunos com deficiência ou altas habilidades ou superdotação notificados ao Censo Escolar no período.

Selecionaram-se, dos resultados da pesquisa de campo, alguns representativos das vivências dos ingressantes do curso, apresentando um quadro de alunos composto em grande maioria $(57,7 \%)$, por jovens entre 18 e 21 anos, do gênero masculino (73,08\%). Há poucos menores de 18 anos $(8,97 \%)$, sendo que o mais jovem tinha 16 anos.

O local de residência de grande parte da turma é a cidade do Rio de Janeiro e a maioria $(64,10 \%)$ habita com os pais. Quanto à instrução dos pais, todos são alfabetizados, sendo que $82,06 \%$ dos pais e $85,90 \%$ das mães têm o ensino médio completo e $24,36 \%$, tanto de pais como de mães são formados no ensino superior.

Nesse panorama, é de se esperar uma situação financeira razoável para a maioria, o que se verifica observando que $65,28 \%$ declararam renda familiar acima de $R \$ 3.500,00$, sendo que mais de um quarto deles (26,39\%), têm-na superior a $\mathrm{R} \$ 7.000,00$. É um contexto que leva a não surpreender com a quantidade dos que viajaram ao exterior, que também é maioria $(53,85 \%)$ e de $76,91 \%$ deles terem cursado o ensino fundamental e médio em escolas privadas. Ainda assim, encontra-se $30,56 \%$ com renda familiar entre $\mathrm{R} \$ 1.500,00$ e $\mathrm{R} \$ 3.500,00$; e outros $4,17 \%$ com a família recebendo entre $\mathrm{R} \$ 1.001,00$ e $\mathrm{R} \$ 1.500,00$. Esses valores evidenciam estudantes que superam dificuldades econômicas para chegar à universidade.

De suas formações culturais, a metade (50\%) dos alunos sabe outra língua além da inglesa, idioma que a ampla maioria (90,48\%) afirma ler de razoável a bem. Eles apresentam bons valores também, como se Olh@ res, Guarulhos, v. 2, n. 1, p. 422-440. Maio, 2014. 
pode inferir com o fato de que $85,90 \%$ deles afirmarem tender a concordar, ou concordarem totalmente, que o plágio de textos da internet não é ético.

Considerando-se os hábitos de leitura, enquanto o mais frequente dado foi o de não ter lido nenhum $(23,08 \%)$ e quase metade $(43,58 \%)$ ter lido até três livros não escolares, um (1,35\%) aluno se destacou, tendo lido 50 .

Os respondentes percebem a informatização do mundo como fato significativo e todos têm computadores com conexão com a internet. Quanto à tecnologia da informação, a grande maioria $(71,79 \%)$ tende a concordar, ou concorda totalmente que é importante para a carreira aprendê-la. E, também, 89,75\% assinalam que irão precisar de mais conhecimentos sobre ela do que tinham ao ingressar na faculdade, além do que, 84,62\% mencionam que há necessidade de ser pró-ativo e independente para aprender novas tecnologias.

A maioria $(59,74 \%)$ teve como local de aprendizagem de grande parte dos softwares a própria casa, onde entre os cinco e 10 anos, 32,0\% deles aprenderam a usar o computador, idades nas quais não se pode creditar como sinal de precocidade na aprendizagem tecnológica, tendo-se em conta o uso que dão ao computador. Diariamente, 70,51\% usam a internet, não tanto para jogos, que é atividade de somente $18,01 \%$ deles, porém, uma boa parte $(76,92 \%)$ utiliza-a para acessar redes sociais diariamente e/ou várias vezes por semana. Usam-na também, várias vezes por semana, quando não é diariamente, para acessarem grupos de discussão $(41,03 \%)$ e chats $(33,33 \%)$. Essas são atividades em que a tecnologia é utilizada em ações de uso quase sempre intuitivo.

Apenas 37,18\% tendem a concordar em estarem melhores posicionados que os colegas em tecnologia da informação (TI) e apenas um $(1,28 \%)$ se considera melhor, o que é uma informação significativa, a partir do fato que essa percepção refere-se a um posicionamento em relação aos colegas do ensino médio, pois ao ingressar não conhece as condições dos colegas ingressantes.

Olh@res, Guarulhos, v. 2, n. 1, p. 422-440. Maio, 2014. 
Dessa forma, se a grande maioria não se percebeu com posicionamento destacado em relação a seus colegas quanto às habilidades em TI, que é uma tecnologia acessível à maioria, não é despropositado afirmar que a escolha da carreira tecnológica não se deve ao fato de se perceberem com facilidade ou potencial elevado para tecnologia. Talvez esse seja o motivo de menos de um quarto $(24,26 \%)$ avaliarem o próprio desempenho como muito bom e, para uma parcela ainda menor $(15,38 \%)$, se sentirem muito bem preparados para a futura profissão.

A maioria $(53,85 \%)$ também considera que a iniciativa de aprender novas tecnologias deve partir dos professores, o que sugere ter autonomia na busca de conhecimentos; ainda em consolidação e para isso confiam na instituição.

Considerando-se esses dados, na diversidade destacada pela triagem para altas habilidades ou superdotação, tem-se um caso, a do leitor que se mostrou voraz naquele contexto e que significativamente foi o que se percebia no uso da TI como sempre melhor posicionado que os colegas.

\section{Considerações Finais}

A identidade cultural de um indivíduo ou de um grupo trata-se da imagem mental de como ele é percebido pelos outros. Esse "retrato" é obtido a partir signos que os caracterizam e é conhecido por identidade cultural. Da ótica das altas habilidades ou superdotação em softwares de computação pessoal e internet, é possível levantar características significativas que compõem esse "retrato" a partir de tratamento de dados coletados por questionários de percepção cultural, isto é, a moldada pela Cultura.

Quanto à identidade cultural de um grupo, pressupõe-se a ocorrência de características comuns entre os seus indivíduos que delineiam a sua imagem. Esse desenho ao destacar o que é comum, estabelece também a ideia da diferença. 
A investigação da identidade cultural de ingressantes do curso de engenharia de produção estudado apresentou como resultado um caso para triagem de potencialidade elevada, ou seja, um estudante entre 78 pesquisados, o que demonstra um indício que o questionário utilizado nesse tipo de pesquisa pode ser visto como um instrumento para coletar percepções do desempenho elevado - altas habilidades ou superdotação.

A possibilidade de indicação de grupos, no caso estudantes de engenharia de produção, pode instrumentalizar $\mathrm{o}$ atendimento especializado previsto nos dispositivos legais e levar a cabo melhores condições educacionais.

Esse uso do questionário de percepção para investigar indícios de desempenho elevado - altas habilidades ou superdotação - permitirá o estudo de casos de grupos populacionais para os quais tenham sido aplicados questionários autoavaliativos, que, por sinal, são instrumentos utilizados para estudos desde a década de sessenta do século passado.

Observa-se na busca de indicadores de altas habilidades ou superdotação pontos a melhorar no questionário de levantamento socioeconômico-cultural utilizado na investigação. Desta forma, concluiu-se a pertinência de conhecimentos nas duas áreas, de Educação Especial e de Estudos Culturais, antevendo a possibilidade de maiores contribuições interdisciplinares. 


\section{Referências}

ALENCAR, Eunice. M. L. S.; FLEITH, Denise. S.Superdotados: determinantes, educação e ajustamento. $2^{\text {a }}$ edição revista e ampliada. São Paulo: EPU, 2001.

BATES, Janet; MUNDAY, Sarah. Trabalhando com alunos superdotados, talentosos e com altas habilidades. Trad. Sueli S. Fidalgo e AngelaCavenaghi-Lessa. São Paulo: Galpão, 2007.

BAUMAN, Zygmunt. Modernidade e ambivalência. Rio de Janeiro: Jorge Zahar, 1999.

BENAVIDES, Maryorie; MAZ, Alexander; CASTRO, Enrique; BLANCO, Rosa (Orgs.). La educación de niños con talento en Iberoamérica. Santiago, Chile: OREALC/UNESCO Santiago, 2004.

BHABBA, Homi K. O local da cultura. Trad. Eliana L. de L. Reis, Gláucia R. Gonçalves. Belo Horizonte: Ed. UFMG, 1998.

BOAVENTURA, Michel. Blog do PSPP. Site. 2011. Disponível em: http://pspp.michelboaventura.com/en/downloads-2/. Acesso em 24 ago. 2012.

BRASIL. Lei de Diretrizes e Bases da Educação Nacional. Lei n. 9.394, de 20 de dezembro de 1996. Disponível em <www.planalto.gov.br/legislação〉. Acesso em 07 abr. 2010.

. Política Nacional de Educação Especial na Perspectiva da Educação
$\begin{aligned} & \text { Inclusiva. } \\ & \text { Brasília: }\end{aligned}$ MEC/SEESP, 2008 . 20 Disponível em:
<http://portal.mec.gov.br/seesp/arquivos/pdf/politica.pdf>. Acesso em 14 ago. 2012.

Decreto no 7.611, de 17 de novembro de 2011. Dispõe sobre a educação

especial, o atendimento educacional especializado e dá outras providências. Brasília:

Presidência da República, 2011. Disponível em:

<http://www.planalto.gov.br/ccivil_03/_Ato2011-2014/2011/Decreto/D7611.htm>.

Acesso em 16 fev. 2011.

Lei 12. 796. Altera a Lei 9.394 de 20 de dezembro de 1996, 2013. Disponível em http://www.planalto.gov.br/ccivil_03/_Ato2011-2014/2013/Lei/L12796.htm\#art1 .

Acesso em 04 dez. 2013.

CANCLINI, Néstor G. Diferentes, desiguais e desconectados. Trad. Luiz Sérgio Henriques. Rio de Janeiro: Ed. UFRJ, 2009.

CHAGAS, Jane Farias. Adolescentes Talentosos: Características Individuais e

Familiares. Tese (DoutoradoemPsicologia). Universidade de Brasília. Brasília, 2009.

DINIZ, Cládice N., OLINTO, G. El uso de la biblioteca y de la tecnología de la información y comunicación para la investigación entre los estudiantes universitarios de

Olh@ res, Guarulhos, v. 2, n. 1, p. 422-440. Maio, 2014. 
Rio de Janeiro: diferencias de género y socioculturales. In: SCIRE (Zaragoza), v.13, p.139 - 157, 2007.

DELOU, Cristina M. C. Lista base de indicadores de superdotação - parâmetros para observação de alunos em sala de aula. Rio de Janeiro: mímeo, 2010.

EAGLETON, Terry. Depois da teoria: Um olhar sobre os estudos culturais e o pósmodernismo. Trad. Maria Lúcia Oliveira. Rio de Janeiro: Civilização Brasileira, 2010. FREITAS, Soraia N.; PÉREZ, Susana G. P. B. Altas habilidades/superdotação: atendimento especializado. Marília: ABPEE, 2012. $2^{\text {a }}$ Ed. Ver. Ampliada.

GUENTHER, Zenita C. Desenvolver capacidades e talentos: um conceito de inclusão. Petrópolis, RJ: Vozes, 2000.

Capacidade e talento. Um programa para a escola. São Paulo: EPU, 2006. Caminhos para desenvolver potencial e talento. Lavras, UFLA, 2011.

GUTIERREZ; Maria del Pilar; MAZ, Alexander. Educación y diversidad. InBenavides, Maryorie; Mas, Alexander; Castro, Enrique; Blanco, Rosa (Orgs.). La educación de niños con talento en Iberoamérica. Santiago, Chile: OREALC / UNESCO Santiago, 2004, p. 13-22.

JULLIEN, François. O diálogo entre as culturas: do universal ao multiculturalismo. Trad. André Telles. Ver. Tec. Danilo Marcondes. Rio de Janeiro: Zahar Ed., 2009. LOPES, Maura C. Inclusão escolar: currículo, diferença e identidade. In: LOPES, Maura Corcini; DAL'IGNA, Maria Cláudia (Orgs.). Exclusão: nas tramas da escola. MELO, Maria Lúcia de A. Subjetividade e conhecimento: Miradas psico(pedagógicas). São Paulo: Vetor, 2002.

MOREIRA, Antonio F. B.; SILVA, Tomaz T. Currículo, cultura e sociedade. São Paulo: Cortez, 1995.

OMOTE, Sadao. Contribuições e limites da abordagem social aplicada ao estudo da deficiência. Simpósio. Palestra no IV Congresso Brasileiro de Educação Especial/VI Encontro da As. Bras. de Pesquisadores em Educação Especial, 2010, São Carlos. ORGANIZAÇÃO DAS NAÇÕES UNIDAS. Declaração de Salamanca sobre Princípios, Políticas e Práticas na Área das Necessidades Educativas Especiais, 
1994. Disponível em: <http://portal.mec.gov.br/seesp/arquivos/pdf/salamanca.pdf>. Acesso em 01 mar. 2011.

RANGNI, Rosemeire, A. Reconhecimento do talento em alunos com perdas auditivas do ensino médio. (Tese de doutorado). Programa de Pós - Graduação em Educação Especial. Universidade Federal de São Carlos, UFSCar, 2012.

SABATELLA, M. L. P. Talento e Superdotação: problema ou solução?Curitiba, Editora IBPEX, 2005.

SASSEN, Saskia. A construção do objeto de estudo digitalizado. In: MACIEL, Maria Lucia; ALB AGLI, Sarita.Informação e desenvolvimento: Conhecimento, inovação e apropriação social. Brasília: IBICT, UNESCO, 2007. P. 33 a 59.

SAHLINS, Marshall D. Cultura na prática. Trad. Vera Ribeiro. Rio de Janeiro: Ed. UFRJ, 2007, Coleção Etnologia.

WALLERSTEIN, I. Impensar a Ciência Social: Os limites dos paradigmas do século XIX. Trad. Adail Sobral, Maria Stela Gonçalves. Aparecida, SP: Ideias \& Letras, 2006, Coleção Caminhos da globalização e as ciências sociais.

WOODWARD, Kathrin. Identidade e diferença: uma introdução teórica e conceitual. In SILVA, 2009, p. 7-72.

VILLARRAGA, Miguel; MARTÍNEZ, Pablo; BENAVIDES, Maryorie.Hacia la definición del término talento.In: BENAVIDES, Maryorie; MAZ, Alexander; CASTRO, Enrique; BLANCO, Rosa (Orgs.). La educación de niños con talento en Iberoamérica. Santiago, Chile: OREALC/UNESCO Santiago, 2004, p.25-33. VIRGOLIM, Ângela M. R. Altas habilidade/superdotação: encorajando potenciais. Brasília: Ministério da Educação, Secretaria de Educação Especial, 2007 